Running Head: MARRIAGE AND DIVORCE ATTITUDES IN EAST ASIA

ATTITUDES TOWARD MARRIAGE AND DIVORCE IN EAST ASIA

A Dissertation

Presented to

the Faculty of the Graduate School

at the University of Missouri-Columbia

In Partial Fulfillment

of the requirements for the Degree

Doctor of Philosophy

by

KWANGMAN KO

Dr. Lawrence Ganong, Dissertation Supervisor \& Academic Advisor

July, 2018 
The undersigned, appointed by the Associate Vice Chancellor of the Office of Research and Graduate Studies, have examined the dissertation entitled

\section{ATTITUDES TOWARD MARRIAGE AND DIVORCE IN EAST ASIA}

Presented by Kwangman Ko,

A candidate for the degree of doctor of philosophy,

And hereby certify that, in their opinion, it is worthy of acceptance

Dr. Lawrence Ganong

Dr. Christine Proulx

Dr. Chelsea Garneau-Rosner

Dr. Phillip K. Wood 


\section{Acknowledgments}

I am very grateful to all of those with whom I have worked with during this dissertation. Each of the members of my Dissertation Committee has provided me with comprehensive professional guidance and encouragement, which helps shape me into a successful family scholar. First of all, many thanks go to my academic advisor, Dr. Lawrence Ganong. As my teacher as well as mentor, he has trained and guided me over the years more than I could ever give him credits for here. I would like to attribute my achievement to Dr. Christine Proulx, who truly has helped me in developing the critical thinking and strategic working process. I am also very thankful for Dr. Chelsea GarneauRosner who has shared with me her precise ideas and constructive suggestions. I am especially grateful for Dr. Phillip Wood, who has honed my skills in quantitative methodology and analytic ability.

No one has been more important to me than my family members in the pursuit of this dissertation. Most of all, my wife Injee, who is my mentor and sole partner, has been unconditionally supportive of me through the years. Words cannot express my gratitude and appreciation for all her sacrifice. I also wish to thank my precious treasure, the loving three wonderful children, Kunwoo, Yeonwoo, and Yeonseo. Special thanks belong to my parents and my younger brother whose love and guidance are always with me. 


\section{Table of Contents}

Acknowledgments...........................................................

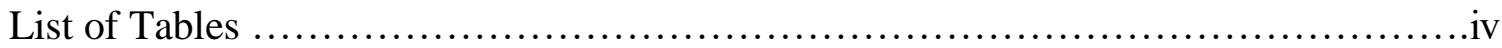

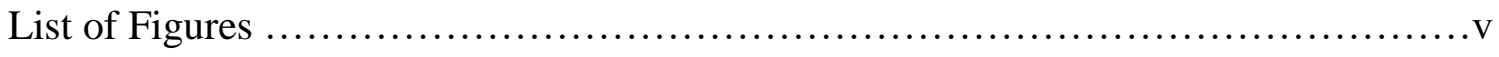

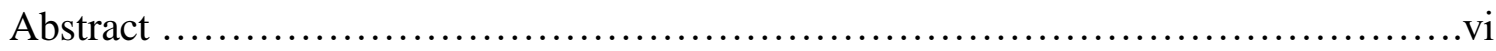

Chapters

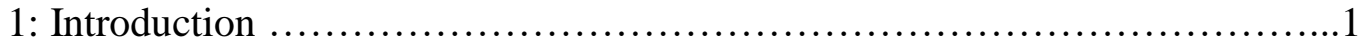

2: Methods ....................................................... 19

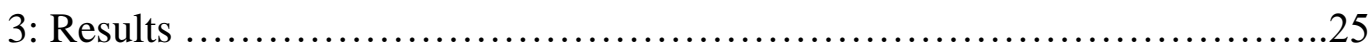

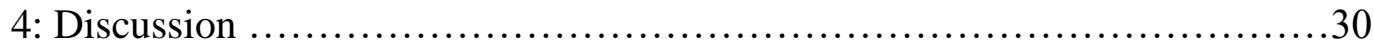

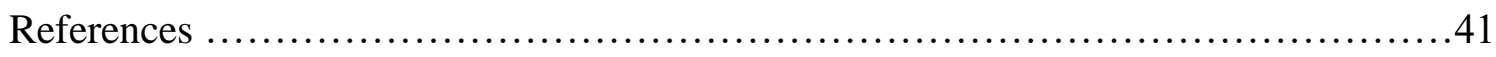

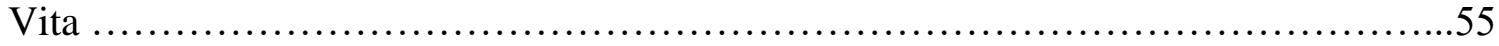




\section{List of Tables}

Table 1. Correlations and descriptive statistics for the six items of marriage and divorce attitudes

Table 2. Results of Explanatory factor analyses of the six items of marriage and divorce attitudes for each country

Table 3. Latent profile analysis statistics and fit indices

Table 4. Cross-tabulation of 4-country and 4-profile

Table 5. Frequency and means (standardized deviation) of demographic variables, patriarchy, and gender role ideology 


\section{List of Figures}

Figure 1. Profile characteristics across six items of marriage and divorce attitudes. 


\begin{abstract}
Attitudes about marriage and divorce, which is related to cultural values and societal norms, are important as they can be indicators of couple relationship quality and marital stability. Along with the rapid social, economic, and cultural changes, East Asians have experienced the major transition of sociocultural interpretations of marriage and divorce. Using a person-oriented approach and the 2006 East Asian Social Survey data set $(N=$ 9,035), this study explored if there were underlying groups of East Asians regarding attitudes toward marriage and divorce. Also, this study examined how those subgroup memberships differed on patriarchy, gender role ideology, age, gender, marital status, education level, and country. Four qualitatively different profiles were identified: conservative (10.8\%), progressive (79.6\%), married men less happy (3.1\%), and married women less happy $(6.5 \%)$. People in the conservative profile, where South Koreans accounted for $45.8 \%$, were more likely to be older, currently married, and less educated. Individuals in the progressive profile were less likely to have traditional patriarchal and gender role ideology, and about $90 \%$ of Chinese and Japanese belonged to this profile. The characteristics of married men less happy and married women less happy group were similar to each other except for the gender ratio and gender role ideology. This study revealed that East Asians have different attitudes toward marriage and family by being categorized into four distinctive groups, which can be implications for policymakers and marriage educators in East Asia.
\end{abstract}




\section{Chapter 1: Introduction}

The purpose of this study is to examine East Asians' attitudes toward marriage and divorce. Specifically, I explored if groupings of Chinese, Japanese, South Koreans, and Taiwanese individuals can be empirically identified from their attitudes about marriage and divorce. A second purpose of the study was to examine how these subgroups differed on patriarchy, gender role ideology, age, gender, marital status, education level, and country.

Why do attitudes toward marriage and divorce matter? Attitudes about marriage and divorce are related to important individual and interpersonal behaviors and outcomes. For example, individuals with favorable attitudes toward marriage: (1) are more likely to get married and tend to marry earlier (Lye \& Biblarz, 1993; Sassler \& Schoen, 1999), and (2) are more likely to be satisfied with their marriages and their lives (Boerner, Jopp, Sosinsky, Kim, \& Carr, 2014; Lev-Wiesel \& Al-Krenawi, 1999; Moss \& Willoughby, 2016). Based on the Waves I and II of the National Survey of Families and Households (NSFH), Sassler and Schoen (1999) found that individuals with positive attitudes toward marriage were more likely to marry. Lye and Biblarz (1993) also identified that lower levels of traditional values of marriage (i.e., disagreeing with "better to marry than go through life being single") were associated with higher levels of marital dissatisfaction (i.e., frequent disagreements with spouse). This may be because people who reject traditional attitudes to marriage are likely to have a positive view of alternatives to marriage such as divorce and place lower values on commitment to marriage. Boerner and her colleagues (2014) reported positive appraisals of marriage were associated with higher marital satisfaction, while Moss and Willoughby (2016) identified individuals 
believing there were advantages of marriage were more likely to satisfy their lives.

Furthermore, individuals with favorable attitudes toward divorce: (1) tend to experience greater declines in marital satisfaction than individuals with less favorable attitudes (Amato \& Rogers, 1999), and (2) are more likely to become divorced (Amato, 1996; Amato \& Booth, 1991), especially if marital quality is low (Whitton, Stanley, Markman, \& Johnson, 2013). Clearly, marriage and divorce attitudes are related to several important indicators of relationship quality and marital stability.

Most of the studies about attitudes toward marriage and divorce have been conducted in the United States and other Western societies. It is not clear if these findings are generalizable to East Asian societies, however, because of differences between Western and Eastern cultures in underlying values and beliefs about individuals, marriages, and families. For instance, individuals with more tolerant attitudes toward divorce are more likely to live in countries with more individualistic cultures (Toth \& Kemmelmeier, 2009). This is not surprising, perhaps, given that attitudes toward marriage and divorce are related to cultural values and societal norms, at least according to several theories. For instance, symbolic interaction theory (Bell \& Cox, 2015; White \& Klein, 2008) states that individuals make sense of their social worlds, which would include attitudes about marriage and divorce, partly by observing cultural norms (e.g., normative beliefs and socially-accepted behaviors) and partly by identifying with primary reference groups whose beliefs and attitudes they admire (e.g., parents, peers, faith-based institutions). The theory of reasoned action also asserts that societal norms influence attitudes, which in turn affect intentions to perform specific behaviors (Fishbein \& Ajzen, $1975 ; 2010)$. 
On the other hand, other researchers have argued that demographic trends influence attitudes and, ultimately, behaviors. For instance, the demographic transition framework is used to understand changes in family formation and organization as well as changes in societal norms about marriage and divorce (Chen \& Li, 2014; Gubernskaya, 2010; Lethaeghe, 2010; Raymo, Park, Xie, \& Yeung, 2015). Demographic transitions are changes, such as reductions in birth and death rates as a country's economy develops with industrialization. Demographers have identified two demographic transitions (Lethaeghe, 2010). The first demographic transition refers to the declines in fertility and mortality in Western countries from the Eighteenth and Nineteenth Centuries, which demographers think contributed to households changing from extended kinship groupings to nuclear families that consisted of two parents and their children (Lesthaeghe, 2010). The second demographic transition occurred during the second half of the Twentieth Century in much of the world. In this transition, the equilibrium between the birth and death rates is not assumed anymore, and the population of a country or a region may decrease without immigrants (Lesthaeghe, 2010). Scholars expected that the second demographic transition should result in: (1) sustained lower birth rates, (2) diverse living arrangements other than marriage, (3) weaker connections between marriage and procreation, (4) delayed marriage or nonmarriage, (5) increases in divorce, and (6) increases in cohabitation (Chen \& Li, 2014; Jones \& Yeung, 2014; Lesthaeghe, 2010). These changes were thought to be accompanied by a lower emphasis on familism and an increased focus on individualism - the second demographic transition was accompanied by sociocultural values such as individual autonomy, self-actualization, rising symmetry in gender roles, refusal of authority, and more flexible life-course trajectories 
(Gubernskaya, 2010). In a study using data from the 1988, 1994, and 2002 waves of the International Social Survey Programme (ISSP), Gubernskaya (2010) found that attitudes toward marriage and children had shifted away from traditional norms of universal marriage and childbearing in Austria, Germany, Great Britain, Ireland, the Netherlands, and the United States over time.

However, other researchers have argued that the second demographic transition framework may not apply well in understanding marriage and family formation in East Asian societies (Ji, 2015; Jones \& Yeung, 2014; Raymo et al., 2015). For instance, although East Asian societies have observed delayed marriage and lower birthrates, as in Western societies, it is still rare to see premarital cohabitation and nonmarital childbirth among contemporary East Asians (Jones \& Yeung, 2014). Also, there still exists a strong connection between marriage and childbearing, which means that married couples are expected to have children (Raymo et al., 2015). Researchers have pointed out that differences in cultural backgrounds may have caused these different trends in marriage and divorce between Western and East Asian societies (Chen \& Li, 2014; Jones, 2010; Jones \& Yeung, 2014).

In terms of cultural backgrounds, Western societies adhere to individualistic cultural norms in which the needs and wants of individuals are more important than group needs and wants (Triandis \& Suh, 2002). In contrast, Asian cultures hold collectivistic values, wherein group stability and order are valued over the pursuit of individuals' goals, wants, and needs. The cultural values of collectivism fit well with beliefs of Confucianism, the predominant faith in East Asia, which stresses marital stability, family harmony, family lineage, and hierarchical power within families (Kung, 
Hung, \& Chan, 2004; Chen \& Li, 2014). Under these traditions, nonmarital childbearing can be still considered taboo, and cohabitation without marriage may only be seen as a precursor to marriage not an alternative to marriage (Raymo et al., 2015).

East Asia's trends in marital dissolution also provide another example of how cultural contexts are related to attitudes toward marriage and divorce. Although divorce historically has been seen as a social problem in nearly every society (Coontz, 2005), attitudes about divorce may be quite different in collectivistic societies than in individualistic ones. For example, Americans may see divorce as an expression of individual spouses' rights to fulfill themselves and to seek personal benefits, whereas residents in collectivistic Asian cultures may be less prone to see the individual advantages of divorce.

Additionally, while Western societies have become accustomed to divorce as a social phenomenon (e.g., divorce rates in the United States peaked decades ago), East Asian societies have only more recently seen a rise in divorce rates. For example, the crude divorce rate (CDR) in China increased about 550\% from 0.3 in 1978 to 2.0 in 2010 (Chen \& Li, 2014; Dommaraju \& Jones, 2011). In the same period, the CDR in South Korea increased about $360 \%$ from 0.5 to 2.3 too. In 2010, the CDRs of Japan (2.0), South Korea (2.3), and Taiwan (2.5) were similar to or higher than that of Western countries such as the United States (3.6), United Kingdom (1.9), and Australia (2.2; Chen \& Li, 2014; Dommaraju \& Jones, 2011; Park \& Raymo, 2013). With the recent increase of divorce rates in the East Asian countries, the personal experiences with divorce, which have been found to be associated with attitudes about marriage and divorce (Amato \& Booth, 1991; Andersson, 2015; Kapinus, 2004), are likely to differ between Western and 
Eastern societies. Therefore, generalizing findings from the West to the East should not be tenable. Given the mix of some changes (e.g., divorce rates) as well as some continuity (e.g., low cohabitation rates) regarding marriage in East Asia, an exploratory study of attitudes toward marriage and divorce among contemporary East Asians is warranted.

\section{Marriage and Divorce in East Asia}

Marriage historically has been one of the most significant social institutions in East Asian societies (China, Japan, South Korea, and Taiwan; Ji, 2015; Raymo et al., 2015). Combined with Confucianism, East Asian familism emphasizes the father/son relationship of the extended family, intergenerational mutual dependence with the hierarchical structure between elder and younger generations, family pride and grace, and rituals worshiping the ancestors (Chen \& Li, 2014). Marriage is seen essential to the fulfillment of family obligations with the transition to adulthood too (Jones \& Yeung, 2014). These traditional values in East Asian societies are related to patriarchal hierarchy and heritage in families, and also have framed divorce as a threat to harmony and order to family and society. Also, patriarchal traditions and prevailing male-dominant gender role ideology in East Asian societies also have favored marital stability and stigmatized divorce (Moghadam, 2004).

However, with rapid modernization and industrialization in East Asia since the second part of the 20th century, traditional values about marriage and divorce have become diluted (Ji, 2015; Jones \& Yeung, 2014; Yang \& Yen, 2011). These social changes have coincided with increasing rates of divorce and the phenomenon of delayed marriage and lower fertility (Kung et al., 2004; Yang \& Yen, 2011). Given that this 
appears to be the characteristics of the second demographic transition that is

accompanied by individualism, it is worth identifying factors related to attitudes toward marriage and divorce, such as cultural values (i.e., patriarchy and gender role ideology) and individuals' demographic characteristics (i.e., gender, age, marital status, and education level). Moreover, it will be worth identifying between-country variation among China, Japan, South Korea, and Taiwan, given that each country has its societal family system such as divorce law.

\section{Patriarchy}

Patriarchy is characterized by men's dominant power, authority, and control for property and even residence (Moghadam, 2004), and patriarchy has been a dominant ideology in East Asia (Jones, 2010). In a patriarchal society, arranged marriages at early ages of women are common, especially by the elder male in a family, and a bride is usually absorbed into the husband's family. However, men get married relatively at older ages because the expectation is that they should be old enough to take responsibility as a head of a household (Jones, 2010). A married woman is regarded as the property of her husband and his family, and she is expected to give birth to children and raise them, be in charge of housework, and also provide support to the husband's parents (Chen \& Li, 2014). Unless they have serious physical or mental disabilities, all women are expected to marry and rarely have access to higher education. Especially, agricultural patriarchal societies emphasize women's premarital virginity and their roles of childbearing and caregiving, which is related to the heir to property such as land and labor force to do farming (International World History Project, 1992). Consequently, unmarried, childless, and divorced women are likely to be socially stigmatized. 
Meanwhile, traditional values of pro-marriage and anti-divorce have been challenged by rapid social and economic changes in East Asia (Ji, 2015). A trend of delayed marriage, less marriage, lower birth rates, and higher divorce rate are reported in this region, which is line with the second demographic transition framework (Raymo et al., 2015). Additionally, arranged marriage and early marriage has decreased, and age differences between husbands and wives have narrowed (Jones, 2010). These phenomena can be seen as signs of deteriorating patriarchal values in East Asia.

\section{Gender Role Ideology}

Gender role ideology indicates general attitudes regarding the appropriate roles and rights of men and women in society (Qian \& Sayer, 2016). In the marriage domain, gender role ideology refers to the internalization of gendered marital roles and marital expectations of men and women (Yang \& Yen, 2011). East Asian cultural contexts may favor gender specialization of roles and family responsibilities: women's greater and men's lesser investment in housework (Oshio, Nozaki, \& Kobayashi, 2013), with men as breadwinners and women as homemakers and caretakers (Meltzer, 2011). Also, the Confucianism is related to gender role ideology (Qian \& Sayer, 2016). In Confucian ideals, the eldest son is expected to live with his parents, who bequeath their property to the son and his wife when they die. This eldest daughter-in-law is expected to care for her residential parents-in-law while she also does housework and takes care of her children. These multigenerational family settings are related to the gendered division of labor in households (Qian \& Sayer, 2016). This unequal gendered division of household labor tends to be negatively related to marital satisfaction (Oshio et al., 2013; Qian \& Sayer, 2016). 
Contemporary East Asians, especially women, experience increasing educational achievements and economic opportunities (Ji, 2015). These changes in East Asian societies have brought perceptions of the fairness of unequal divisions of labor, which can be related to more egalitarian gender role ideology (Qian \& Sayer, 2016). Egalitarian gender role ideology values men and women equally and believes in shared family roles in breadwinning and homemaking/caretaking. People having more egalitarian gender role ideology are likely to be unsatisfied with the traditionally gendered unequal division of roles in marriage, making them less satisfied with marriage and more favorable toward divorce (Yang \& Yen, 2011).

\section{East Asian Countries}

East Asian countries indicate China, Japan, South Korea, and Taiwan (Chen \& Li, 2014; Ji, 2015; Yang \& Yen, 2011). Although the four countries have shared the traditional values of Confucian familism and have shown similar trends regarding marriage, divorce, and family relationships, between-country variations also exist (Chen \& Li, 2014; Jones \& Yeung, 2014; Raymo et al., 2015; Yang \& Yen, 2011). For instance, later marriage seems obvious in East Asian countries except China in that the mean age at first marriage of females in 2010 was about 29-year-old in Japan, South Korea, and Taiwan, while it was about 24-year-old in China (Raymo et al., 2015). In terms of the fertility rates, China, South Korea, and Taiwan have shown similar trends. The Total Fertility Rates (TFR), the average number of children a woman would have if she survives all her or reproductive years, started dropping from the 1970s and has reached very low levels: China (1.9), South Korea (1.2), and Taiwan (0.9) in 2010. However, Japan already experienced fertility declines from the 1950s, and its TFR in 1975 was 1.9 
(Chen \& Li, 2014). China may be unique as it had enforced a one-child policy from 1979 to 2015. Under this policy, parents can invest their resources on fewer children, and the younger generation in China is likely to have higher academic achievements, which may be related to less conservative attitudes toward marriage and divorce (Qin, Zhunag, \& Yang, 2017). Furthermore, the female labor force participation rate in 2010 was higher in China (63.5\%) and Japan (63.2\%) than in South Korea (49.2\%) and Taiwan (49.6\%) (Raymo et al., 2015). These statistics may be meaningful in that women's participation in the labor market can give them more economic independence, which has been found to be related to less traditional marriage and divorce attitudes (Chen \& Li, 2014). Among these four East Asian countries, Japan was the first to experience modernization and industrialization and has become the most economically developed to date. Economic development also may be related to cultural values related to family life, marriage, and divorce. For instance, Hashimoto and Ikels (2005) reported that the core value of filial piety in Confucian familism was weaker among Japanese than Chinese. Lesthaeghe (2010) argued that Japanese had more favorable attitudes toward cohabitation than other Asian countries except for the Philippines.

Attitudes toward marriage and divorce are also related to law and policy systems (Chen \& Li, 2014; Raymo et al., 2015). In particular, divorce rates, divorce laws, and social attitudes toward divorce are interconnected (Hiller \& Recoules, 2013). In Japan, the divorce process is straightforward, and most divorces are obtained through mutual agreement (McCauley, 2011). Unlike other East Asian countries, modern Japanese society embraced the principle of gender equality in its legal system even in the 1950s after World War II. However, the family law systems in Japan have not changed much 
since then, and these laws are unique regarding divorced parents' visitation and custody (McCauley, 2011). For example, in Japan, only one parent is allowed to acquire and maintain legal custody after a divorce, and non-custodial parents rarely have contact with their nonresident child(ren). In China, until the late 1970s, getting divorced was very hard as it required the approval of the state. Although marriage law reforms in the 1980s made getting divorced relatively easier, married couples were still required to have permission from their employers to get divorced. However, the new divorce law enacted in 2003 secured women's property rights after separation and liberalized divorce in favor of women, including removing the requirement for permission from an employer, which resulted in rising divorce rates in China (Sun \& Zhao, 2016). When a divorce occurs, the custody of a child under two-years-old is given to the mother, and for a child older than two, the custody is usually given to the parent who represents better the interests of the child (Sun \& Zhao, 2016). In South Korea, family laws were established in 1960 in the contexts of patriarchy and hierarchy in family relationships. In 1990, the laws were revised to enhance women's legal standing by endowing stay-at-home wives with the right to file for the division of property and by securing the equal custodial rights of mothers upon divorce (Shim, Choi, \& Ocker, 2013). In the 2000s, revision of laws was oriented for "the best interest of children" in the form of securing child support payments and expanding joint-custody (Shim et al., 2013). Like South Korea, the main point of family law system in Taiwan was the clash between traditional Chinese values of marriage and divorce in Taiwan and the principle of human equality. The family law system has developed enhancing equal rights in marriage and divorce such as enabling wives to obtain property in its property ownership system and offering each spouse the 
same possibility of obtaining a divorce (Chen, 2005). Custody decisions in Taiwan are also made by considering child's best interest rather than giving priority to fathers, as the Taiwan courts tend to favor the mothers.

Overall, Japan, South Korea, and Taiwan are more economically developed than China, and these three countries have shown similar trends in marriage and divorce, such as delayed marriage and lower childbirth rates (Jones \& Yeung, 2014). Considering Japan has been strongly influenced by Western culture since the late Nineteenth Century, Japanese may be assumed to have more progressive attitudes toward marriage and divorce than other East Asians. China is unique in terms of its political system and onechild policy. Given the higher women's labor market participation, Chinese may have more progressive egalitarian gender role ideology than South Koreans or Taiwanese.

\section{Demographic Factors Related to Marriage and Divorce Attitudes}

Gender. Gender may be an influential factor related to attitudes toward marriage and divorce in East Asia. Under the patriarchal tradition, men are allowed to have more propriety and authority than females in marriage. Also, Confucian tradition emphasizes the father-son axis in extended family systems. Given these traditions, men are more likely to have conservative attitudes toward marriage and divorce. Moreover, East Asian women have experienced marital package (Ji, 2015; Jones \& Yang, 2014). This means that although women have more access to education and participation in the labor force than in the past, they are still expected to be responsible for childbearing and childrearing as well as supporting other family members such as their husbands' parents (Chen \& Li, 2014). 
Meanwhile, gender differences in divorce attitudes have not been found consistently across studies. For example, in a study of divorced women in Hong Kong, (Kung et al., 2004) reported that women showed more conservative attitudes to divorce, which may reflect their greater costs of divorce compared to men regarding economic insecurity and stigma. In contrast, in a study with contemporary Japanese, South Koreans, and Taiwanese, women were more likely than men to agree that divorce was a solution for a failing marriage and disagreed that divorce should be delayed until after children have grown (Yang \& Yen, 2011).

Age. Age may be related to attitudes toward marriage and divorce in East Asian societies. Japan, China, South Korea, and Taiwan have been through rapid industrial and economic development since the second half of the Twentieth Century. As the second demographic transition suggests, social and economic development is followed by the changes from emphasizing familism to individualism, which can be related to change of attitudes toward marriage and family (Lesthaeghe, 2010). Upon this rapid change, it is plausible that there is a generation gap among contemporary East Asians; older individuals have more conservative marriage and divorce attitudes. Bumpass and Choe (2004) reported that there was a clear cohort trend in Japanese and South Koreans in terms of acceptability of divorce; older cohorts were more likely to agree with the statement that, "parents should not divorce for the sake of the children." The researchers argued that changing social expectations of traditional values of marriage may have affected the younger generation more than older ones.

However, Yang and Yen (2011) reported different results in a divorce study with Japanese, South Koreans, and Taiwanese. They divided their study participants into four 
age groups: $18-29,30-39,40-49$, and 50-59 years old. Compared to the 18-29 age group, the two groups of 30-39 and 50-59 disagreed strongly with that one should delay divorce until children become 18 years old, and also all the other groups agreed strongly with that divorce could be an option when a marriage fails. This might be because divorce has become prevalent in East Asian societies since the 1980s (Dommaraju \& Jones, 2011), which may affect people's attitudes to divorce too.

Marital status. Individuals' marital status can affect their attitudes toward marriage and divorce. In a study identifying the relations between family life course and attitudes toward divorce in Sweden, Andersson (2015) reported that married individuals were less likely to have favorable divorce attitudes. Yang and Chen (2011) also found that compared to married people, single/unmarried people were more likely to agree to the idea of divorce as the best solution when a marriage fails to work among Japanese, South Koreans, and Taiwanese. Moreover, in East Asian societies, marital status can be highly related to parental status, as there are have a higher expectation of childbearing in married life (Raymo et al., 2015). For instance, in the 2006 East Asian Social Survey of China, Japan, South Korea, Taiwan, about $82 \%$ of married individuals had at least one child in their marriage. Toth and Kemmelmeier (2009) argued that having children can be a reason for a couple to decide to remain married because growing up with both parents is often considered beneficial for children.

Education. Educational achievement is another factor that may be related to attitudes toward marriage and divorce. Through increasing access to educational opportunities, individuals, especially women, are more likely to have economic ability and less likely to have traditional values of marriage and divorce as they obtain financial 
independence (Chen \& Li, 2014; Yang \& Yen, 2011). Raymo and his colleagues (2015) reported in a study of marriage and family in East Asia that education levels in Japan, South Korea, and Taiwan were related to later marriage - highly educated individuals are more likely to delay marriage. However, less educated individuals in the most recent cohort in China were likely to delay marriage, which might be because those people look less attractive as potential spouses in the marriage market (Raymo et al., 2015). Also, cohabitation is more common among Japanese women with lower education while cohabitation in China is positively associated with education attainment (Raymo et al., 2015).

Regarding divorce, higher education levels will be positively related to the likelihood of marital dissolution where divorce is rare and its social and economic cost is high (Chen \& Li, 2014). As divorce becomes prevalent and more accepted, the cost of divorce becomes lower, and the relations between education level and divorce weakens. However, some studies identified a negative educational gradient in divorce in Korea and Japan, which indicates that people with lower levels of education were more likely to get divorced (Park \& Raymo, 2013; Raymo, Fukuda, \& Iwasawa, 2014).

\section{Person-Oriented Approach to Attitudes toward Marriage and Divorce}

Most previous research studying marriage and divorce attitudes have taken a variable-oriented approach, which focuses on examining correlations among variables and predicting outcomes (Bergman \& Trost, 2006). For instance, Yang and Yen (2011) identified the relations between gender role attitudes and divorce attitudes, and Andersson (2015) found how experiencing life course events were associated with divorce attitudes. Whereas variable-oriented approaches are interested in relations among 
variables, person-oriented approaches focus on relationships among people (Collins \& Lanza, 2010). In other words, the focus of person-oriented approaches is on patterns of operating factors among individuals. By taking person-oriented approaches, researchers can identify sub-groups of people based on their similarities on a set of variables (Bergman \& Trost, 2006). Thus, based on the assumption of an unobservable heterogeneous population consisting of subgroups of individuals, a person-oriented approach can help researchers to identify qualitatively different groups based on shared characteristics and similarities in response patterns. For example, there may be a group of people who hold negative attitudes about divorce in general but who may have more positive attitudes under specific conditions such as having a child(ren) to support. Considering that East Asian societies have been experiencing the transition of norms and expectations of marriage and divorce, it is plausible that the attitudes toward marriage and divorce among East Asians are diverse. Moreover, given that attitudes are affected by personal experiences (Fishbein \& Ajzen, 1975, 2010; Kapinus, 2004), taking a personoriented approach may be a relevant strategy to examine individuals' attitudes toward marriage and divorce.

The person-oriented approach about attitudes toward marriage and divorce may be beneficial to researchers, practitioners, and policymakers. This approach may affect education evaluations. In a meta-analysis based on 117 studies of the efficacy of marriage and relationship education, Hawkins, Blanchard, Baldwin, and Fawcett (2008) found that the effect sizes for relationship quality for experimental studies were modest but significant, ranging from $d=.30$ to .36 , while those for quasi-experimental studies were not significant. However, these results may be different when subpopulations of 
participants are considered, given that program effectiveness can be different across individuals. For instance, participants who were female, younger, less educated, and had lower income showed the most benefit from a parent education program (Feng \& Fine, 2000; Schramm \& McCaulley, 2012). With the person-oriented approach, Researchers can identify individuals who share similar characteristics in a group and will be able to evaluate program effectiveness for different subgroups of people. The person-oriented approach also can be useful to educators and practitioners, given that they can consider characteristics of subgroups of people and provide more group-oriented instruction and tailored content to them (Bastaits, Ponnet, Peer, \& Mortelmans, 2015; Galovan \& Schramm, 2017). For instance, Galovan and Schramm (2017) suggested in a divorced parent program that for subgroups of participants showing positive coparenting relationships, parenting program educators may highlight maintaining coparenting behaviors while they still discuss inter-parental conflict after divorce. This personoriented approach to marriage and divorce may have implications for policymakers in East Asia. As marriage and family formation is traditionally regarded as the foundation of a society, most governments have the policy of encouraging marriage and discoursing singlehood in the national level (e.g., limiting tax benefits; Jones \& Yeung, 2014). If this study reveals different subgroups of people having similar attitudes toward marriage and divorce, the result can represent that there exist diverse ideas of family formation and stability among contemporary East Asians. Also, policymakers may consider developing a more group-oriented approach. For instance, it may be possible to intensify workfamily balance policy for unmarried women who have favorable attitudes toward 
marriage in the aim of lowering their expectation of "marital package" burden ( $\mathrm{Ji}, 2015$; Jones \& Yang, 2014).

\section{Current Study}

East Asians' interpretations of marriage and divorce have been undergoing major transformations and transitions under the rapid social, economic, and cultural changes (Huang, 2015; Raymo et al., 2015). Given this situation, it is reasonable that East Asians have diverse attitudes toward marriage and divorce rather than uniform, homogenous attitudes. Using a person-oriented approach, I explored if there were underlying groups of individuals in East Asia regarding attitudes toward marriage and divorce. Also, I examined how patriarchy, gender role ideology, age, gender, marital status, education level, and country were related to those subgroup memberships. 


\section{Chapter 2: Method}

\section{Sample}

Data for this study were taken from the 2006 East Asian Social Survey (EASS), which is based on four GSS-type surveys in East Asia: Chinese General Social Survey (CGSS), Japanese General Social Survey (JGSS), South Korean General Social Survey (KGSS), and Taiwan Social Change Survey (TSCS). Across the four countries, the survey was conducted in households with adults aged 18 or over from June to December in 2006, and 9,045 in total took part in the survey. Except for ten people who did not answer all the questions of marriage and divorce attitudes, all the participants were included in the study $(N=9,035)$. Among the participants, $35.5 \%$ were Chinese were $(n=$ 3,207), $23.5 \%$ were Japanese $(n=2,124), 17.7 \%$ were South Koreas $(n=1,602)$, and $23.3 \%$ were Taiwanese $(n=2,102)$.

Participants in this study were nearly equally divided by gender ( $46.3 \%$ male and $53.7 \%$ female). They ranged in age from 20 to $92(M=45.48, S D=16.01)$. Across the four countries, $31.0 \%$ completed higher secondary education, $17.4 \%$ finished above lower qualification (= middle school education), $15.9 \%$ finished lowest formal qualification (= elementary school), and $15.2 \%$ were university degree holders. Regarding annual household income level, the median value of Chinese currency was $15,800 ¥$ (about $\$ 1,982$ in 2006), and that of South Korean currency was $28,000,000$ (about $\$ 29,316$ in 2006). In Japan, the median range of household income was 4,500,000 to $5,500,000 \mathrm{JP} ¥$, (about $\$ 38,686$ to $\$ 47,283$ in 2006) and that of Taiwan was 60,000 to 70,000 NT $\$$, (about $\$ 18,428$ to $\$ 21,499$ in 2006 ). 
A substantive number $(3,748 ; 41.5 \%)$ identified themselves as full-time employees, followed by self-employed $(n=1,502 ; 16.6 \%)$, and homemakers $(n=1,116$; $12.3 \%)$. Regarding marital status, $71.2 \%$ were currently living as married $(n=6,432)$, $18.9 \%$ were single never married $(n=1,708)$, and $6.5 \%$ were widowed $(n=586)$. Most $(58.8 \%)$ participants reported that they had no religion, while $18.2 \%$ were Buddhists, and $14.0 \%$ chose "other Eastern religion."

\section{Measures}

Attitudes toward marriage and divorce. Six items were used to assess attitudes toward marriage and divorce: (1) "husband should be older than wife," (2) "It's not necessary to have children in marriage," (3) "married men happier than unmarried," (4) "married women happier than unmarried," (5) "it's okay to live together without getting married," and (6) "divorce is usually the best solution when marriage goes wrong." Each item was rated on a seven-point Likert scale from 1 'strongly agree' to 7 'strongly disagree.' The first, the third, the fourth item were reverse coded for the analysis so that higher scores meant more traditional/conservative attitudes toward marriage and divorce.

Patriarchy. The 2006 EASS has six items of patriarchal value: (1) the authority of father in a family should be respected under any circumstances, (2) children must make efforts to do something that would bring honor to their parents, (3) the eldest son should inherit a larger share of the property, (4) a child who has taken good care of parents should inherit a larger share of the property, and (5) to continue the family line, one must have at least one son. Each item was rated on a seven-point Likert scale from 1 'strongly agree' to 7 'strongly disagree.' All the items were reverse coded for the analysis so that higher scores indicate higher levels of patriarchal value. 
Among these items, the fourth item of "inheriting a large share of property" was not significantly related to the second item of "honoring parent" and was moderately correlated with the first item of "authority of father" $(r=.09, p<.01)$. To identify if there were multiple constructs across the five items (Pituch \& Stevens, 2016), I ran explanatory factor analyses (EFAs) using Mpuls version 8 with maximum likelihood estimation and geomin rotation. The results showed that a two-factor model had the best model fit: Comparative Fit Index $(\mathrm{CFI})=.99$, Tucker Lewis index $(\mathrm{TLI})=.97$, Root Mean Square Error of Approximation $($ RMSEA $)=.04(90 \%$ CI $=[.02, .06])$, Standardized Root Mean Square Residual $(\mathrm{SRMR})=.01$. The first and second item of patriarchy showed higher correlations with factor 1 (i.e., at least |.30|; Harlow, 2014) and the other three showed higher correlations with factor 2. Factor 1 is about hierarchy (authority and honoring), and factor 2 is related to heritage (lineage and son-preference). Therefore, I used the composite score of the first and second item under the name of patriarchy-hierarchy and the composite score of the third, fourth and fifth item as the name of patriarchy-heritage.

Gender role ideology. Four items exist in 2006 EASS: (1) "it is more important for a wife to help her husband's career than to pursue her own career"; (2) "a husband's job is to earn money; a wife's job is to look after the home and family"; (3) "men ought to do a larger share of household work than they do now"; and (4) "during economic recession, it is all right for women to be laid-off before men." All the items were rated on a seven-point Likert scale from $1=$ 'strongly agree' to $7=$ 'strongly disagree.' All the items except the third were reverse coded for the analysis so that higher scores mean more traditional gender role ideology. Among these items, the third item of "men's larger share of housework" was moderately correlated with the first item of "helping husband" 
$(r=.04, p<.01)$ and the second item of "husband and wife's job" $(r=.06, p<.01)$. I ran EFA (maximum likelihood estimation and geomin rotation), and one factor model showed the best fit: $\mathrm{CFI}=.99, \mathrm{TLI}=.98, \mathrm{RMSEA}=.040(90 \% \mathrm{CI}=[.03, .05]), \mathrm{SRMR}$ $=.01$. However, as the factor loading of the third item was very low $(\lambda=.07)$, I used the composite score of the first, second, and fourth item of gender role ideology for the analysis.

Demographic factors and country. Respondents' demographic characteristics of age, gender, marital status, and education level were considered as indicators related to attitudes toward marriage and divorce. Regarding marital status, I created a new categorical variable of living as married or not from the question asking the participant's marital relationship (i.e., widowed, divorced, separated, and cohabiting). Also, I used the country variable, a categorical variable indicating China, Japan, South Korea, and Taiwan.

\section{Analysis Plan}

First, I ran the correlation analysis to see how the six items of marriage and divorce attitudes were interrelated across the four countries in East Asia (see Table 1). Most items were significantly correlated at the significance level of .01, and a higher positive correlation $(r=.71, p<.01)$ was found between "married men happier than unmarried" and "married women happier than unmarried." Some items were not significantly related to each other (e.g., "married men happier than unmarried" and "divorce is usually the best solution when a marriage goes wrong").

Next, I conducted correlation analysis of the six items of marriage and divorce for each country to identify if the relationships among items were similar for each country. 
The results showed that each country might have different ideas of attitudes toward marriage and divorce. For instance, for the items of "husband should be older than wife" and "it's not necessary to have children in marriage," only China showed a positive association $(r=.83, p<.01)$, while other countries showed negative associations. Based on this result, I conducted EFAs for each country to identify if there was a similar pattern of factors in terms of marriage and divorce attitudes. Table 2 shows the models having best fits for each country: China - one-factor model, Japan and Taiwan - two-factor model, and South Korea - three-factor model. This indicates that the participants in each country may have different constructs regarding marriage and divorce attitudes. Therefore, the person-oriented approach across the countries, focusing on relationships among people, may be a better analytic approach regarding attitudes toward marriage and divorce among East Asians.

I conducted latent profile analysis (LPA), a kind of finite mixture modeling (Berlin, Williams, \& Parra, 2014). Based on the scores of variables of interest, LPA is used to identify latent profiles that have similar characteristics among members of a profile. LPA also provides the likelihood of belonging to a specific profile for each respondent. To explore underlying profiles regarding attitudes toward marriage and divorce among East Asians, I considered the six items in 2006 EASS. LPA has an assumption of local independence, which means that the relationships among a set of variables in a profile are to be zero (Collins \& Lanza, 2010). However, as the correlation between the item of "married men happier than unmarried" and "married women happier than unmarried" was high $(r=.71, p<.01)$, I took LPA with partial conditional 
independence approach by allowing covariance between the two items (Muthén \& Muthén, 1998-2017). I also used the maximum likelihood estimator in the analysis. In terms of deciding which model is best, a few fit indices were considered (Berlin et al., 2014; Collins \& Lanza, 2010). For the Akaike Information Criterion (AIC) and Bayesian Information Criterion (BIC), the latent profile with the smallest values on AIC and BIC is considered to be the best fitting model. Entropy statistic is a measure of classification certainty. The entropy ranges from 0 to 1 , where values near one indicating high certainty in classification. Also, Lo-Mendell-Rubin Adjusted Likelihood Ratio Test (LMR-LRT) was used to compare models with different numbers of profiles. In detail, a non-significant LMR-LRT value indicates the model with one fewer profiles explains the data better. However, researchers do not rely on only these fit indices when deciding the best model having a certain number of classes as they also consider theories, results of previous studies, and look for a parsimonious model (Berlin et al., 2014; Collins \& Lanza, 2010). After the number of latent profiles was determined, estimates of the proportion of individuals in each profile were made (Collins \& Lanza, 2010).

Next, I ran multivariate analysis of variance (MANOVA) to identify the characteristics of each profile in terms of patriarchy-hierarchy, patriarchy-heritage, gender role ideology, age, gender, marital status, and education level (Pituch \& Stevens, 016). To confirm where the differences occurred across the four profiles, I ran the Tukey post-doc tests, which provides all the pairwise comparison across the profiles. The country variable was also considered to understand how profiles were different from each other. 


\section{Chapter 3: Results}

\section{Latent Profile Analysis}

To address my first goal, I ran LPA using Mplus 8.0 (Muthén \& Muthén, 19982017) to explore if there were underlying groups of people regarding marriage and divorce attitudes among contemporary East Asians. To find the best fitting model, I referred to the AIC, BIC, Entropy, and LMR-LRT while specifying models with two to six latent profiles. The statistics of each model are shown in Table 3. The 4-profile model seemed the most appropriate as it showed the lowest AIC and BIC value, the closet to 1 regarding Entropy and the LMR-LRT was not significant in the 5-profile model. Figure 1 shows the four profiles and the scores of the six items. Higher scores reflected more traditional attitudes toward marriage and divorce.

The first profile was labeled conservative $(n=978 ; 10.8 \%)$, as individuals in this profile reported the highest scores across the six items of marriage and divorce attitudes among the four profiles. Particularly, they showed more traditional values of childbearing in marriage and cohabitation. They were much more likely to think that "husband should be older than wife" and "married men/women are happier than unmarried men/women," and less likely to agree with the idea of divorce as a solution when a marriage goes wrong.

The second profile was labeled, married men less happy $(n=278 ; 3.1 \%)$. People in this profile reported somewhat higher scores in the items of the age gap between husband and wife, childbearing in marriage, and cohabitation. Interestingly, they had the lowest scores in the item of "married men are happier than unmarried," while they showed the highest scores to the item of "married women are happier than unmarried." 
Additionally, people in this group reported the second lowest score in the item of

"divorce as a solution when a marriage goes wrong," which reflects less traditional attitudes toward divorce.

The third profile was labeled as married women less happy $(n=583 ; 6.5 \%)$. The overall tendency of marriage and divorce attitudes of this profile was similar to that of the married men less happy profile. However, these two profiles had the opposite responses to the items of "married men/women happier than unmarried." Individuals in this profile agreed more with the idea of "married men are happier than unmarried" and agreed less with the idea of "married women are happier than unmarried." Like the married men less happy group, people in this profile reported the second lowest score regarding the item of "divorce as a solution when a marriage goes wrong."

The fourth profile was the largest group and labeled as progressive $(n=7,196$; 79.6\%). People in this profile reported nearly even scores to all the six items of marriage and divorce attitudes. They showed relatively less traditional attitudes about the age gap between husband and wife, childbearing in marriage, and cohabitation. Also, unlike the married men less happy and the married women less happy profile, the scores of items of "married men happier" and "married women happier" were similar in this profile.

Regarding the country, Table 4 shows the cross-tabulation of 4-country and 4profile. The result of chi-squire test was significant at $\alpha=.05\left(X^{2}(9)=1009.97, p<.001\right)$, which indicates that the country and the profile membership are not independent each other (Agresti, 2007). The sample was 35.5\% Chinese, 23.5\% Japanese, 17.7\% South Koreas, and $23.3 \%$ Taiwanese. Within each profile, $45.8 \%$ of the conservative profile was South Koreans, followed by Taiwanese (23.6\%), Japanese (15.4\%), and Chinese 
$(15.1 \%)$. In the married men less happy profile, Taiwanese were the largest population (43.9\%), and Chinese were the second largest population (32.7\%). In married women less happy profile, Taiwanese were also the largest population (43.9\%), while the percentages of Chinese and Japanese in this profile were similar (23.8\% and 22.1\%, respectively). Finally, the progressive profile showed similar proportions as the entire sample: $39.3 \%$ of Chinese, $26.3 \%$ of Japanese, $13.8 \%$ of South Koreas, and $20.6 \%$ of Taiwanese. Next, with regard to the profile ratio in each country, about $90 \%$ of the Chinese and Japanese participants belonged to the progressive profile ( $88.2 \%$ and $89.2 \%$, respectively), followed by Taiwanese (70.4\%) and South Koreans (61.9\%). Among the four countries, South Korea showed the highest within-country percentage of falling into the conservative profile (28.0\%), and Taiwan recorded the second highest (11.0\%).

\section{Multivariate Analysis of Variance}

Each profile showed a few distinctive demographic characteristics (see Table 5). While the conservative and married men less happy profile showed a similar gender ratio, about $52 \%$ male and $48 \%$ female, the married women less happy profile consisted of $36 \%$ of male and $64 \%$ female. In terms of age, individuals in the conservative profile $\left(M_{a g e}=54.09 ; S D=15.78\right)$ were more likely to be older than people in other profiles as the mean of age in the married women less happy and progressive profiles was about 45 years old, followed by the married men less happy profile $\left(M_{\text {age }}=42.59 ; S D=15.67\right)$. Regarding marital status, nearly $80 \%$ of the conservative profile were currently married, while about $66 \%$ of the married men less happy profile were currently married. The married women less happy and progressive profiles consisted of about $70 \%$ of married 
individuals. Also, the conservative profile had relatively lower education levels than the other profiles.

I conducted the MANOVA to assess profile differences regarding the study variables of gender, age, marital status, education level, patriarchy-hierarchy, patriarchyheritage, and gender role ideology. Individuals were assigned to attitudes toward marriage and divorce profile membership based on the solution of the latent profile analyses, and the 4-profile MANOVA was performed in SPSS 24.0. The independent variable was the four profile memberships, and the dependent variables were the study variables such as age and gender role ideology. The profiles were significantly different in terms of the study variables based on profile membership when using Pillai's trace criterion, $F(28,36000)=450.23, p<.001$, partial $\eta^{2}=.26$. Follow-up univariate analyses of variance (ANOVAs) for each dependent variable revealed that the profiles significantly differed on gender, age, marital status, education level, patriarchy-hierarchy, patriarchy-heritage, and gender role ideology. Table 5 also shows the results of the Tukey post-hoc tests that revealed where the difference occurred across the four profiles. First, regarding the gender ratio, only the married women less happy profile where $64 \%$ was female was different from all other profiles. Second, the conservative profile was different from all other profiles regarding individuals' age and marital status; they were more likely to be older and married. The conservative profile also had less education than other profiles, reported the highest levels of patriarchy-hierarchy, patriarchy-heritage, and gender role ideology. In terms of beliefs about patriarchy-hierarchy, the conservative profile held significantly more patriarchal attitudes than any of the other profiles, the married men less happy and married women less happy profiles did not differ from each 
other, but the progressive profile reported significantly lower patriarchy-hierarchy attitudes. In levels of hierarchy-heritage attitudes, the conservative group was significantly more traditional than all other profiles. In regards to gender role ideology, the conservative profile was again significantly more traditional than all of the other profiles, and the married men are less happy was significantly more traditional than the married women less happy and the progressive profiles, who did not differ from each other. 


\section{Chapter 4: Discussion}

East Asian societies have experienced rapid Westernization and industrialization since the mid-Twentieth century, which has influenced cultural values about families. East Asians have seen a rise in non-traditional phenomena such as delayed marriage, lowered fertility, and rising divorce rates, which are typical trends of the second demographic transition framework, along with moving from familism to individualism as broad cultural values (Lesthaeghe, 2010). However, other aspects of this framework, such as increased cohabitation and non-marital childbearing, are still rare among East Asian societies (Jones \& Yeung, 2014).

In this study, I examined contemporary East Asians' attitudes toward marriage and divorce. Moreover, by taking the person-oriented approach, I aimed at identifying underlying heterogeneous groups with similar marriage and divorce attitudes. This study extends previous research by revealing four qualitatively different profiles of contemporary East Asians across China, Japan, South Korea, and Taiwan. Also in this study I found significant differences among the four profiles in beliefs about patriarchy and gender role ideology, as well as demographic differences in age, gender, marital status, and education. Between-country differences also were identified.

\section{Profiles of Marriage and Divorce Attitudes}

I used the six items related to the attitudes toward marriage and divorce in 2006 EASS and found four heterogeneous subgroups of people by running LPA: conservative, married men less happy, married women less happy, and progressive. Those profiles, although empirically determined, are not vastly different in many ways. 
First, about $11 \%$ of the participants were classified in the conservative profile, which contains older, more likely married, and less educated individuals than the other groups. This is not surprising as all of these demographic characteristics are related to traditional attitudes in most societies. The mean of age in this profile was about ten years older than that of other profiles, which may reflect a cohort trend of cultural value in marriage and divorce in East Asian societies (Bumpass \& Choe, 2004; Ji, 2015). Older individuals are less favorable to changes in societal attitudes and behaviors, and they tend to think about marriage, divorce, and family life in more conservative ways that are more consistent with the era in which they were raised. Also, the marriage rate of this profile was significantly higher than that of other profiles, which may be related to traditional manners to both childbearing in marriage and divorce as a solution to unhappy marriage (Andersson, 2015; Yang \& Yen, 2011). This is because the marital status is highly related to parental status in East Asia (Raymo et al., 2015) and parental status is also associated with the unfavorable divorce attitudes (Toth \& Kemmelmeier, 2009). Individuals in this profile showed the lowest education level, which is in line with the results of previous studies; increased educational opportunities bring economic independence and less traditional value in marriage and divorce (Chen \& Li, 2014; Yang \& Yen, 2011). Furthermore, it is also not surprising that the conservative profile held stronger patriarchal beliefs than the other groups, with more traditional (male-dominated) attitudes about gender roles than the other profiles (Ji, 2015; Oshio et al., 2013; Qian \& Sayer, 2016). The second demographic transition framework may not work well with this conservative profile, because the values such as individual autonomy, egalitarian gender 
roles, and the refusal of authority may not be compatible with the conservative characteristics of this profile (Gubernskaya, 2010).

Meanwhile, South Koreans took nearly $50 \%$ of the conservative profile, and they were also less likely to fall into the progressive profile in terms of within-country composition than Chinese, Japanese, and Taiwanese (Table 4). This finding may indicate that South Koreans have more traditional attitudes toward marriage and divorce rather than Chinese, Japanese, and Taiwanese. However, South Korea is a member of OCED, which represents its developed economy and industrialization, and the typical aspects of the second demographic transition such as later marriage, lower fertility, and increased divorce rates have observed in South Korea (Dommaraju \& Jones, 2011; Jones \& Yeung, 2014). This discrepancy may be understood by the concept of compressed modernity, which indicates that mutually heterogenous historical elements or cultural values coexist because of the economic, political, and sociocultural changes occurring in an extremely condensed manner in time and space (Chang, 2010; Chen \& Li, 2014). Chang (2010) argued that the explosively rapid economic development since the 1960s has abridged the time from low-income agricultural economy to advanced industrial economy in South Korea. These rapid changes have accompanied by Western ideology such as individualistic values in family formation and continuity, but the traditional values of pro-marriage and anti-divorce may still exist and affect South Koreans' attitudes toward marriage and divorce. For instance, the very lower rank of South Korea in the Gender Gap Report 2016, the $116^{\text {th }}$ out of 144 countries, may reflect the traditional gender role ideology, as lower ranks represented more disparity between men and women regarding health, education, economy and politics (World Economic Forum, 2016). Along with this 
gender role inequality, conservative values such as emphasizing gender role in marriage and intensive motherhood are observed in South Korea, which may be related to the finding of this study (Chen \& Li, 2014).

Second, while the most surprising finding of the conservative profile may be that so few individuals $(10.8 \%)$ were in this group, the majority of East Asian adults in the sample (79.6\%) was categorized as progressive. In contrast to the conservative profile, the progressives were not different demographically from any group except the conservatives. They did differ in patriarchal beliefs about hierarchy from all other profiles and were similar in gender role beliefs to the married women are less happy group. The traditional patriarchal values of pro-marriage and anti-divorce seem to be moderate in this group of people $(\mathrm{Ji}, 2015)$. This profile also showed more egalitarian gender role ideology, which is related to perceiving the fairness of traditionally unequal division of domestic labor, being less favorable marriage attitudes, and more tolerant divorce attitudes (Yang \& Yen, 2011). However, it should be noted that this group was progressive only in relative terms - their attitudes about marriage and divorce tended to be in the middle of the 7-point response ranges, with means generally slightly toward the conservative, traditional end of the item scales. They were less traditional than the other profiles, however, which was why they were labeled progressive.

A large number of individuals in the progressive profile, coupled with the midpoint attitudinal responses, may suggest that there has indeed been a gradual change in "family values" among these East Asian countries. Although this is cross-sectional data, I speculate that what these data represent is a measured shifting of attitudes from traditional, conservative, and patriarchal to a slow acceptance of less conventional views. 
Although the second demographic transition framework seems to suggest broad, sweeping changes to societies, transformations of ancient cultural beliefs do not happen quickly (Greenfield, 2009), and what the data may be showing is a snapshot of societies in the midst of large changes. It appears that collectivistic values related to familism are still strong in these East Asian countries, but there are signs that large numbers of individuals hold attitudes that are accepting of divorce as a solution to marital problems, who do not strongly adhere to traditional gender roles, and who are not in favor of patriarchal traditions. Additionally, as the social attitudes about a phenomenon and the laws related to the phenomenon are usually interconnected (Hiller \& Recoules, 2013), the legal systems of marriage and divorce in East Asian societies may be changed to reflect people's marriage and divorce attitudes. Therefore, longitudinal studies are needed to assess whether this speculation is true or not.

Meanwhile, it may be noteworthy to point out that about $90 \%$ of Chinese were identified as the progressive profile (Table 4). From the perspective of the second demographic transition, Chinese may be assumed to have more traditional attitudes toward marriage and divorce than those Japanese, South Koreans, and Taiwanese, where later marriage or non-marriage, lower fertility rate, and rise in divorce are more distinctively observed (Qian \& Sayer, 2016; Raymo et al., 2015). The Communist Party in China encouraged women's labor force participation to boost economic development and to achieve gender equality with the policy of equal pay legislation and liberal maternity leave (Qian \& Sayer, 2016). For instance, China ranked $99^{\text {th }}$ out of 144 countries in the Gender Gap Report 2016, which was a much higher ranking than Japan $\left(111^{\text {th }}\right)$ and South Korea $\left(116^{\text {th }}\right)$. Given women's participation in the paid-labor market is 
related to their economic independence, this relatively higher rank may help explain why the majority of the Chinese were in the progressive profile (Chen \& Li, 2014). Also, the one-child policy in China, from 1979 to 2015, may be the key to understand the finding (Chen \& Li, 2014; Hesketh, Lu, \& Xing, 2005; Liu, 2017). The one-child policy can be related to the characteristics of the people who were mainly born in the 1980s. This generation is more likely to be well educated and more economically independent, as parents can put more resources to fewer children (Qin et al., 2017). Also, this generation is more likely to have a stronger sense of self and less likely to follow traditional authority (Hesketh et al., 2005). All these characteristics may be related to the more progressive attitudes toward marriage and divorce. Moreover, the one-child policy may be more influential to women as they can have more access to education, which may not be possible when they have more siblings, especially brothers, as China has had the tradition of son-preference (Hesketh et al., 2017). Also, women under the one-child policy can spend less time for childcare and housework and more time for themselves such as pursuing careers, which can weaken the traditional gender role ideology. Taken together, the contemporary Chinese may have less traditional marriage and divorce attitudes than expected.

The two profiles left are the married women less happy (6.5\%) and the married men less happy $(3.1 \%)$. These two profiles differed from each other primarily on who benefits most from marriage - men or women. In detail, these two groups were similar to each other on most demographic characteristics and attitudes, differing only in the proportions of each profile that were male and female and in adherence to gender role ideologies. They did not differ on patriarchal beliefs, however, which suggests that the 
main focus of these two profiles was on the marital relationship and marital functioning rather than on broader family issues or on gender as it related to parent-child relationships (i.e., son-preference). In a conservative-progressive continuum, these profiles fall somewhere in between the ends, with the primary distinctions being their responses to questions about who is happier when they are married, men or women. Perhaps not surprisingly, the married women are less happy profile had many more females than the other groups. Given the factors of the gender ratio and gender role ideology, the individuals in the married women are less happy profile may think marriage is less beneficial to women and perceive the marriage as a package, the dual burden for women of housework labor and cultural beliefs of childrearing as well as supporting other family members (Chen \& Li, 2014). In other words, the package of family expectations and obligations involved marriage may make marriage unattractive to individuals, especially to women. On the contrary, the individuals in the married men less happy profile may think marriage is less beneficial to males than females. This profile was different from the married women less happy group regarding the equal gender ratio and more traditional gender role ideology.

Furthermore, it should also be noted that a high proportion of individuals in these two profiles were Taiwanese (about $45 \%$ of each profile; see Table 4). Taiwan was greatly over-represented in these two gendered profiles, which suggests that gender roles within marriage are of particular salience for Taiwanese adults. For instance, Yu (2015) reported that the "inverse-the V-shaped" labor force participation curve for Taiwanese women, which means that women are less likely to return to the paid work once they have children. Also, while the traditional value of men's gender roles as a breadwinner is 
still prevalent, the men's decreasing labor force participation (from $78 \%$ in 1978 to $67 \%$ in 2015) may cause men to feel a burden to support family members and make marriage less attractive (Chen \& Li, 2014; Yu, 2015). However, it cannot be determined from these data why Taiwanese held the nearly half of these two profiles. It may be that gender roles in marriage are undergoing changes in Taiwan due to policy shifts, increasing awareness of gender issues brought to the forefront by groups of citizens (e.g., women's rights groups, marital reform advocates). It is difficult to speculate why Taiwanese seemed to care so much about gender and marriage, but the results indicate this is an issue that is more relevant to Taiwan than to the other three countries in the data set.

\section{Limitations}

Although this study contributes to the literature of attitudes toward marriage and divorce in East Asian societies, a few limitations exist. This study used the 2006 East Asian Social Survey (EASS) that is based on four nationwide general social surveys from China, Japan, South Korea, and Taiwan. As the surveys were conducted in 2006, a decade ago, the results of this study may not reflect the East Asians' present attitudes about marriage and divorce. For instance, South Koreans may show less traditional attitudes now than when they survey was administered because the complexity of social systems caused by compressed modernity may be attenuated over time. Additionally, as the surveys of 2006 EASS were conducted with only East Asians, it is not possible to compare the results of this study to those of other studies examining marriage and divorce attitudes in Western societies. Conducting surveys with the same measurements about marriage and divorce attitudes in Eastern and Western societies and comparing the results would be necessary to explore the similarities and differences between culturally 
different societies. Moreover, as with any secondary data set, I was limited to what was asked in the survey. It seems unlikely that six items can adequately capture the complexity of attitudes toward divorce and marriage, so the findings should be interpreted with this limitation in mind. Another data set limitation concerned the measurement of income, which has been found to be related to marriage and divorce attitudes, as higher income levels can lead to economic independence, especially for women, which is associated with to less traditional attitudes toward marriage and divorce (Raymo et al., 2015). However, there was no common income variable measured across the four countries in the 2006 EASS, so I used education level as the indicator of socioeconomic status. Moreover, future research may identify within-country variations of marriage and divorce attitudes. For instance, China has the second largest country in the world and has experienced rapid economic development over decades (U.S. News, 2018). This has brought discrepancies between urban and rural areas in terms of education achievements, job opportunities, and economic prosperity (Guo, Chi, \& Silverstein, 2012). As Greenfield (2009) argued that there is a dominant direction of social change in history, which involves being more urban, educated, richer, and independent, it is plausible that urban residents have more progressive marriage and divorce attitudes than rural residents in China.

\section{Implications}

The findings of this study have a few implications. First, the governments in this region regard family formation and continuity as the foundation for a strong society, which may be related to less favorable policies to being singlehood or cohabitation (Jones \& Yeung, 2014). At least the results of this study show the majority of East Asians have 
relatively less traditional values in marriage and divorce. Thus, policymakers may consider more progressive family policy in the near future to lessen the gap between the policy goals and the people's beliefs and attitudes. Second, the results of this study can be referred to relationship and marriage education, as it is important for family educators or couple therapists to understand how the class attendees and clients think of marriage and divorce (Huang, 2005). For instance, people in the conservative profile may show unfavorable manner to divorce. Also, individuals, especially females, in the married women less happy profile may be much less satisfied with the gender inequality in housework. By understanding the characteristics of their customers, family educators or couple therapists may be able to provide more efficient programs (Huang, 2005).

\section{Conclusion}

This study identified four qualitatively different profiles of East Asians about attitudes toward marriage and divorce, which reflects there can exist diverse values and views of family formation and continuity across Chinese, Japanese, South Koreans, and Taiwanese. Although it may be surprising only about $10 \%$ of the participants fell into the conservative profile, it was obvious the group adhered to more traditional values of patriarchy and gender role ideology. Additionally, about $80 \%$ of the East Asians were categorized as the progressive profile. Attention should be paid in interpreting this result because this progressive is a relative term. However, given the individuals in this group showed similar attitudes to all the six items of marriage and divorce, East Asians may be able to see rises in cohabitation and nonmarital childbirth in the future, which will allow researchers to fully apply the second demographic transition framework to understand 
marriage and divorce in East Asia. Each profile showed a few distinctive characteristics in term of the ratio of the nationality, which should be studied further in the future. 


\section{References}

Agresti, A. (2007). An Introduction to Categorical Data Analysis (2nd ed.). Hoboken, New Jersey: John Wiley \& Sons.

Amato, P. R. (1996). Explaining the intergenerational transmission of divorce. Journal of Marriage and Family, 59, 628-640. doi: 10.2307/353723

Amato, P. R., \& Booth, A. (1991). The consequences of divorce for attitudes toward divorce and gender roles. Journal of Family Issues, 12, 306-322. doi: $10.1177 / 019251391012003004$

Amato, P. R., \& Rogers, S. J. (1999). Do Attitudes Toward Divorce Affect Marital Quality? Journal of Family Issues, 20, 69-86.

Andersson, L. (2015). Gender, family life course and attitudes toward divorce in Sweden. Acta Sociologica, 59(1), 51-67. doi: 10.1177/0001699315615639

Bastaits, K., Ponnet, K., Peer, C. V., \& Mortelmans, D. (2015). The parenting styles of divorced fathers and their predictors. Journal of Social and Personal Relationships, 32, 557-579. doi: 10.1177/0265407514541070

Bell, D. B., \& Cox, M. L. (2015). Social norms: Do we love norms too much? Journal of Family Theory and Review, 7, 28-46. doi:10.1111/jftr.12059

Bergman, L. R., \& Trost, K. (2006). The person-oriented versus the variable-oriented approach: Are they complementary, opposites, or exploring different worlds? Merrill-Palmer Quarterly, 52, 601-632.

Berlin, K. S., Williams, N. A., \& Parra, G. R. (2014). An introduction to latent variable mixture modeling (part 1): Overview and cross-sectional latent class and latent 
profile analyses. Journal of Pediatric Psychology, 39, 174-187. doi:

10.1093/jpepsy/jst085

Boerner, K., Jopp, D. S., Sosinsky, L., Kim, S.-K., \& Carr, D. (2014). "His" and "her" Marriage? The role of positive and negative marital characteristics in global marital satisfaction among older adults. The Journals of Gerontology: Series B, 69, 579-589. https://doi.org/10.1093/geronb/gbu032

Bumpass, L. L., \& Choe, M. K. (2004). Attitudes relating to marriage and family life. In N. O. Tsuya \& L. L. Bumpass (Eds.), Marriage, Work and Family Life in Comparative Perspective: Japan, South Korea and the United States (pp. 19-38). Honolulu: University of Hawaii Press.

Chang, K-S. (2010). Compressed modernity and its discontents: South Korean society in transition. Economy and Society, 28, 30-55, doi: 10.1080/03085149900000023

Chen, H-S. (2005). Changes in Marriage and Family-Related Laws in Taiwan: From Male Dominance to Gender Equality. In: W-H. Lin \& H-C. Hsieh (Eds.), Gender, Culture \& Society: Women's Studies in Taiwan, (pp. 389-416). Seoul: Ewha Womans University Press.

Chen, Y-CC., \& Li, J-CA. (2014). Family change in East Asia. In J. Treas, J. Scott, \& M. Richards (Eds.), The Wiley Blackwell Companion to the Sociology of Families, (pp. 61-82). Chichester, UK: Wiley.

Collins, L. M., \& Lanza, S. T. (2010). Latent class and latent transition analysis: With applications in the social, behavioral, and health sciences. Hoboken, NJ: Wiley.

Coontz, S. (2005). Marriage, a history: How love conquered marriage. New York, NY: Viking. 
Dommaraju, P., \& Jones, G. (2011). Divorce trend in Asia. Asian Journal of Social Science, 39, 725-790. doi: 10.1163/156853111X619201

Feng, P., \& Fine, M. A. (2000). Evaluation of a research-based parenting education program for divorcing parents. Journal of Divorce \& Remarriage, 34(1/2), 1-23. https://doi.org/10.1300/J087v34n01_01

Fishbein, M., \& Ajzen, I. (1975). Belief, attitude, intention, and behavior: An introduction to theory and research. Reading, MA: Addison-Wesley.

Fishbein, M., \& Ajzen, I. (2010). Predicting and changing behavior: The reasoned action approach. New York, NY: Psychology Press.

Galovan, A. M., \& Schramm, D. G. (2017). Initial coparenting patterns and postdivorce parent education programming: A latent class analysis. Journal of Divorce and Remarriage, 58(3), 212-226. https://doi.org/10.1080/10502556.2017.1303320

Greenfield, P. M. (2009). Linking social change and developmental change: Shifting pathways of human development. Developmental Psychology, 45, 401-418.

Gubernskaya, Z. (2010). Changing attitudes toward marriage and children in six countries. Sociological Perspectives, 53, 179-200. doi: 10.1525/sop.2010.53.2.179

Guo, M., Chi, I., \& Silverstein, M. (2012). The structure of intergenerational relations in rural China: A latent class analysis. Journal of Marriage and Family, 74, 11141128. https://doi.org/10.1111/j.1741-3737.2012.01014.x

Harlow, L. L. (2014). The essence of multivariate thinking: Basic themes and methods. New York: Routledge. 
Hawkins, A. J., Blanchard, V. L., Baldwin, S. A., \& Fawcett, E. B. (2008). Does marriage and relationship education work? A meta-analytic study. Journal of Consulting and Clinical Psychology, 76, 723-734. doi: 10.1037/a0012584

Hesketh, T., Lu, L., \& Xing, Z. W. (2005). The effect of China's one-child family policy after 25 years. The New England Journal of Medicine, 353, 1171-1176.

Hiller, V., \& Recoules, M. (2013). Changes in divorce patterns: Culture and the law. International Review of Law and Economics, 34, 77-87. doi: 10.1016/j.irle.2013.01.002

Huang, W-J. (2005). An Asian perspective on relationship and marriage education. Family Process, 44, 161-173. https://doi.org/10.1111/j.1545-5300.2005.00051.x International World History Project. (1992). Women in patriarchal societies. Retrieved from http://history-orld.org/Civilization,\%20women_in_patriarchal_societies.htm Ji, T. (2015). Asian families at the crossroads: A meeting of East, West, tradition, modernity, and gender. Journal of Marriage \& Family, 77, 1031-1038. doi: 10.1111/jomf.12223

Jones, G. W. (2010). Changing marriage patterns in Asia. Singapore: Asia Research Institute, National University of Singapore.

Jones, G. W., \& Yeung, W-J. J. (2014). Marriage in Asia. Journal of Family Issues, 35, 1567-1583. doi: 10.1177/0192513X14538029

Kapinus, C. A. (2004). The effect of parents' attitudes toward divorce on offspring's attitudes: Gender and parental divorce as mediating factors. Journal of Family Issues, 25, 112-135. doi: 10.1177/0192513X02250860 
Kung, W. W., Hung, S-L., \& Chan, C. L. W. (2004). How the socio-cultural context shapes women's divorce experience in Hong Kong. Journal of Comparative Family Studies, 35, 33-50.

Lesthaeghe, R. (2010). The unfolding story of the second demographic transition. Population and Development Review, 36, 211-251. doi: 10.1111/j.17284457.2010.00328.x

Lev-Wiesel, R., \& Al-Krenawi, A. (1999). Attitude towards marriage and marital quality: A comparison among Israeli Arabs differentiated by religion. Family Relations, $48,51-57$.

Liu, Y. (2017). Women rising as half of the sky? An empirical study on women from the one-child generation and their higher education participation in contemporary China. Higher Education, 74, 963-978.

Lye, D. N., \& Biblarz, T. J. (1993). The effects of attitudes toward family life and gender roles on marital satisfaction. Journal of Family Issues, 14, 157-188.

McCauley, M. J. (2011). Divorce and the welfare of the child in Japan. Pacific Rim Law \& Policy Journal, 20, 589-606.

Meltzer, S. (2011). Our divorce culture: A Durkheimian perspective. Journal of Divorce \& Remarriage, 52(3), 147-163. doi: 10.1080/10502556.2011.556962

Moghadam, V. M. (2004). Patriarchy in transition: Women and the changing family in the Middle East. Journal of Comparative Family Studies, 35, 137-162.

Moss, E., \& Willoughby, B. J. (2016). Associations between beliefs about marriage and life satisfaction: the moderating role of relationship status and gender. Journal of Family Studies, 24, 1-17. doi:10.1080/13229400.2016.1187658 
Muthén, L.K. and Muthén, B.O. (1998-2017). Mplus User’s Guide (8th ed.). Los Angeles, CA: Muthén \& Muthén.

Oshio, T., Nozaki, K., \& Kobayashi, M. (2013). Division of household labor and marital satisfaction in China, Japan, and Korea. Journal of Family and Economic Issues, 34, 211-223. https://doi.org/10.1007/s10834-012-9321-4

Park, H., \& Raymo, J. M. (2013). Divorce in Korea: Trends and educational differentials. Journal of Marriage and Family, 75, 110-126. doi: 10.1111/j.17413737.2012.01024.x

Pituch, K. A., \& Stevens, J. P. (2016). Applied multivariate statistics for the social sciences: Analyses with SAS and IBM's SPSS (6th ed.). New York, NY: Routlege.

Qian, Y., \& Sayer, L. (2016). Division of labor, gender ideology, and marital satisfaction in East Asia. Journal of Marriage and Family, 78, 383-400. doi: 10.1111/jomf. 12274

Qin, X., Zhunag, C. C., \& Yang, R. (2017). Does the one-child policy improve children's human capital in urban China? A regression discontinuity design. Journal of Comparative Economics, 45, 287-303. doi: 10.1016/j.jce.2016.09.001

Raymo, J. M, Fukuda, S., \& Iwasawa, M. (2014). Educational differences in divorce in Japan. Demographic Research, 28, 177-206. doi:10.4054/DemRes.2013.28.6

Raymo, J. M., Park, H., Xie, Y., \& Yeung, W. J. (2015). Marriage and family in East Asia: Continuity and change. Annual Review of Sociology, 41, 471-492. doi: 10.1146/annurev-soc-073014-112428

Sassler, S., \& Schoen, R. (1999). The effect of attitudes and economic activity on marriage. Journal of Marriage and Family, 61, 147-159. doi: 10.2307/353890 
Schramm, D. G., \& McCaulley. G. (2012). Divorce education for parents: A comparison of online and in-person delivery methods. Journal of Divorce \& Remarriage, 53(8), 602-617. https://doi.org/10.1080/10502556.2012.721301

Shim, H., Choi, I., \& Ocker, B. L. (2013). Divorce in South Korea: An introduction to demographic trends, culture, and law. Family Court Review, 51, 578-590. https://doi.org/10.1111/fcre.12054

Sun, A. \& Zhao, Y. (2016). Divorce, abortion, and the child sex ratio: The impact of divorce reform in China. Journal of Development Economics, 120, 53-69. https://doi.org/10.1016/j.jdeveco.2015.11.006

Toth, K., \& Kemmelmeier, M. (2009). Divorce attitudes around the world: Distinguishing the impact of culture on evaluations and attitude structure. CrossCultural Research, 43, 280-297. doi: 10.1177/1069397109336648

Triandis, H. C., \& Suh, E. M. (2002). Cultural Influences on personality. Annual Review of Psychology, 53, 133-160. https://doi.org/10.1146/annurev.psych.53.100901.135200

U.S. News. (2018). Best Countries 2018. Retrieved from https://www.usnews.com/news/best-countries/china

White, J.M., \& Klein, D. M. (2008). Family theories (3rd ed.). Los Angeles, CA: Sage.

Whitton, S., Stanley, S., Markman, H., \& Johnson, C. (2013). Attitudes toward divorce, commitment, and divorce proneness in first marriages and remarriages. Journal of Marriage \& Family, 75, 276-287. doi: 10.1111/jomf.12008

World Economic Forum. (2016, October 26). The Global Gender Gap Index 2016. Retrieved from http://reports.weforum.org/global-gender-gap-report-2016/ 
Yang, W-S., \& Yen, P-C. (2011). A comparative marital dissolution in East Asian societies: Gender attitudes and social expectations toward marriage in Taiwan, Korea, and Japan. Asian Journal of Social Science, 29, 751-775. doi:

$10.1163 / 156853111 X 619210$

Yu, W-H. (2015, September 14). Women and employment in Taiwan. Retrieved from https://www.brookings.edu/opinions/women-and-employment-in-taiwan/ 
Table 1. Correlations and descriptive statistics for the six items of marriage and divorce attitudes $(N=9,045)$

\begin{tabular}{|c|c|c|c|c|c|c|}
\hline & 1 & 2 & 3 & 4 & 5 & 6 \\
\hline $\begin{array}{l}\text { 1. Husband should be } \\
\text { older than wife }\end{array}$ & - & & & & & \\
\hline $\begin{array}{l}\text { 2. It's not necessary to } \\
\text { have children in } \\
\text { marriage }\end{array}$ & $-.09 * *$ & - & & & & \\
\hline $\begin{array}{l}\text { 3. Married men } \\
\text { happier than } \\
\text { unmarried }\end{array}$ & $.18 * *$ & $-.12^{* *}$ & - & & & \\
\hline $\begin{array}{l}\text { 4. Married women } \\
\text { happier than } \\
\text { unmarried }\end{array}$ & $.15^{* *}$ & $-.16^{* *}$ & $.71 * *$ & - & & \\
\hline $\begin{array}{l}\text { 5. It's OK to live } \\
\text { together without } \\
\text { getting married }\end{array}$ & $-.13 * *$ & $.36^{* *}$ & $-.09 * *$ & $-.06 * *$ & - & \\
\hline $\begin{array}{l}\text { 6. Divorce is best } \\
\text { when a marriage } \\
\text { goes wrong }\end{array}$ & $.04 * *$ & $.13 * *$ & -.01 & .01 & $.12 * *$ & - \\
\hline$M$ & 4.47 & 3.40 & 4.41 & 4.30 & 3.47 & 4.08 \\
\hline$S D$ & 1.29 & 1.58 & 1.25 & 1.23 & 1.54 & 1.51 \\
\hline
\end{tabular}


Table 2. Results of Explanatory factor analyses of the six items of marriage and divorce attitudes for each country

\begin{tabular}{lcccc}
\hline & China & Japan & South Korea & Taiwan \\
\hline $\begin{array}{l}\text { Number of } \\
\text { factors }\end{array}$ & one & two & three & two \\
AIC & $59,335.82$ & $36,302.89$ & $33,976.65$ & $46,442.07$ \\
BIC & $59,445.13$ & $36,433.07$ & $34,073.47$ & $46,572.03$ \\
CFI & .81 & .99 & .99 & .99 \\
TLI & .69 & .97 & .99 & .96 \\
RMSEA & .14 & .05 & .03 & .04 \\
{$[90 \%$ CI $]$} & {$[.13, .15]$} & {$[.04, .07]$} & {$[.00, .05]$} & {$[.02, .06]$} \\
SRMR & .07 & .02 & .01 & .02 \\
\hline
\end{tabular}


Table 3. Latent profile analysis statistics and fit indices $(N=9,035)$

\begin{tabular}{|c|c|c|c|c|c|c|c|c|c|c|}
\hline \multirow[b]{2}{*}{ Profiles } & \multirow[b]{2}{*}{ AIC } & \multirow[b]{2}{*}{$\mathrm{BIC}$} & \multirow[b]{2}{*}{ Entropy } & \multirow[b]{2}{*}{$\begin{array}{l}\text { LMT- } \\
\text { LRT }\end{array}$} & \multicolumn{6}{|c|}{$\begin{array}{c}\text { Average latent class/profile } \\
\text { probabilities }\end{array}$} \\
\hline & & & & & 1 & 2 & 3 & 4 & 5 & 6 \\
\hline 1 & $183,292.56$ & $183,384.96$ & & & & & & & & \\
\hline 2 & $180,558.09$ & $180,700.21$ & 0.96 & $.00 * * *$ & .99 & .83 & & & & \\
\hline 3 & $179,103.82$ & $179,295.68$ & 0.69 & $.00 * *$ & .95 & .86 & .81 & & & \\
\hline 4 & $176,637.66$ & $176,879.26$ & 0.87 & $.00 * *$ & .94 & .99 & .80 & .99 & & \\
\hline 5 & $176,151.49$ & $176,442.83$ & 0.70 & .82 & .80 & .98 & .67 & .77 & .98 & \\
\hline 6 & $174,757.91$ & $175,098.99$ & 0.77 & .68 & .99 & .85 & .99 & .69 & .78 & .99 \\
\hline
\end{tabular}

Note. Bolded text indicates the best fitting solution. AIC = Akaike Information Criterion; $\mathrm{BIC}=$ Bayesian Information Criterion; LMT-LRT $=$ Lo-Mendell-Rubin Adjusted Likelihood Ratio Test.

$* * p<.01, * * * p<.001$. 
Table 4. Cross-tabulation of 4-country and 4-profile $(N=9,035)$

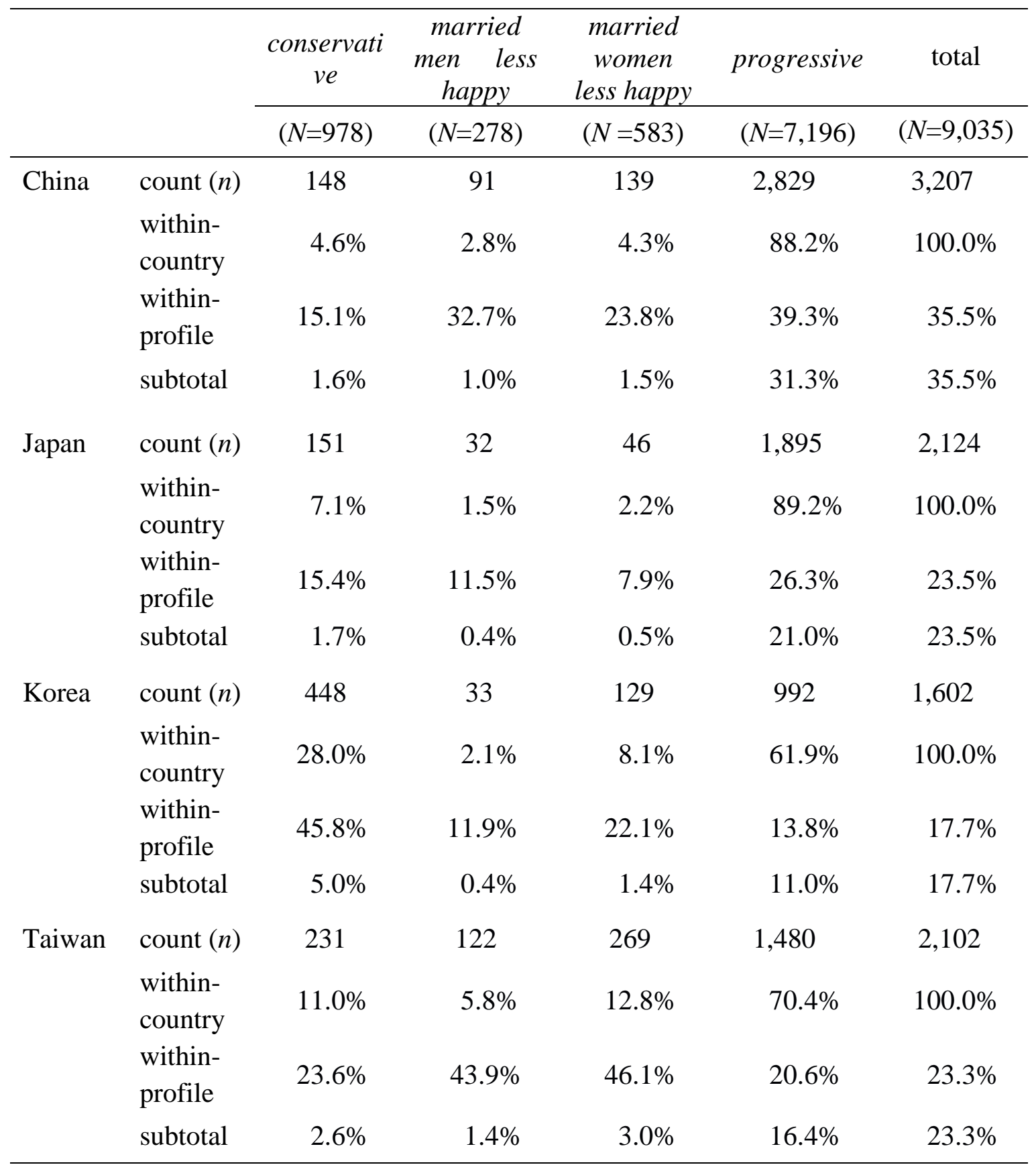


Table 5. Frequency and means (standardized deviation) of demographic variables, patriarchy, and gender role ideology

\begin{tabular}{|c|c|c|c|c|c|}
\hline & 1 & 2 & 3 & 4 & \multirow[b]{2}{*}{$\begin{array}{c}\text { Profile } \\
\text { differences }^{\mathrm{c}} \\
(p<.05)\end{array}$} \\
\hline & $\begin{array}{c}\text { conservativ } \\
e \\
(N=978)\end{array}$ & $\begin{array}{c}\text { married } \\
\text { men less } \\
\text { happy } \\
(N=278)\end{array}$ & $\begin{array}{c}\text { married } \\
\text { women } \\
\text { less happy } \\
(N=583)\end{array}$ & $\begin{array}{l}\text { progressive } \\
(N=7,196)\end{array}$ & \\
\hline Gender & & & & & $3>1,2,4$ \\
\hline Male & $52.1 \%$ & $52.5 \%$ & $35.8 \%$ & $46.1 \%$ & \\
\hline Female & $47.9 \%$ & $47.5 \%$ & $64.2 \%$ & $53.9 \%$ & \\
\hline Age & $\begin{array}{c}54.09 \\
(15.78)\end{array}$ & $\begin{array}{c}42.59 \\
(15.67)\end{array}$ & $\begin{array}{c}44.60 \\
(15.25)\end{array}$ & $\begin{array}{c}44.49 \\
(15.76)\end{array}$ & $1>2,3,4$ \\
\hline Marital status & & & & & $1>2,3,4$ \\
\hline Married & $79.9 \%$ & $65.5 \%$ & $71.4 \%$ & $70.2 \%$ & \\
\hline Not married & $20.1 \%$ & $34.5 \%$ & $28.6 \%$ & $28.6 \%$ & \\
\hline Education & & & & & $2,3,4>1$ \\
\hline No formal & $11.1 \%$ & $3.2 \%$ & $6.3 \%$ & $5.7 \%$ & \\
\hline Lowest formal & $22.1 \%$ & $18.7 \%$ & $14.4 \%$ & $15.0 \%$ & \\
\hline Above formal & $14.7 \%$ & $20.9 \%$ & $19.9 \%$ & $17.4 \%$ & \\
\hline $\begin{array}{r}\text { Higher } \\
\text { secondary }\end{array}$ & $26.8 \%$ & $29.1 \%$ & $8.0 \%$ & $31.9 \%$ & \\
\hline Above higher & $9.6 \%$ & $15.1 \%$ & $14.8 \%$ & $14.6 \%$ & \\
\hline $\begin{array}{r}\text { University } \\
\text { degree }\end{array}$ & $15.4 \%$ & $12.9 \%$ & $16.3 \%$ & $15.2 \%$ & \\
\hline Patriarchy- & 11.76 & 10.85 & 10.97 & 10.37 & \\
\hline hierarchy ${ }^{a}$ & $(2.03)$ & $(2.37)$ & $(2.27)$ & $(2.12)$ & $1>2,3>4$ \\
\hline Patriarchy- & 14.58 & 12.44 & 12.50 & 12.82 & $1>2.3 .4$ \\
\hline heritage $e^{b}$ & (3.56) & $(3.70)$ & $(3.56)$ & (2.98) & $1>2,3,4$ \\
\hline $\begin{array}{l}\text { Gender role } \\
\text { ideology }\end{array}$ & $\begin{array}{l}13.51 \\
(3.76)\end{array}$ & $\begin{array}{l}12.29 \\
(3.83)\end{array}$ & $\begin{array}{l}11.59 \\
(3.98)\end{array}$ & $\begin{array}{l}11.66 \\
(3.37)\end{array}$ & $1>2>3,4$ \\
\hline
\end{tabular}

Note. ${ }^{a}$ Range is 2 to $14 .{ }^{b}$ Range is 3 to $21 .{ }^{c}$ Profile differences are based on the Tukey post-hoc test. 
Figure 1. Profile characteristics across six items of marriage and divorce attitudes.

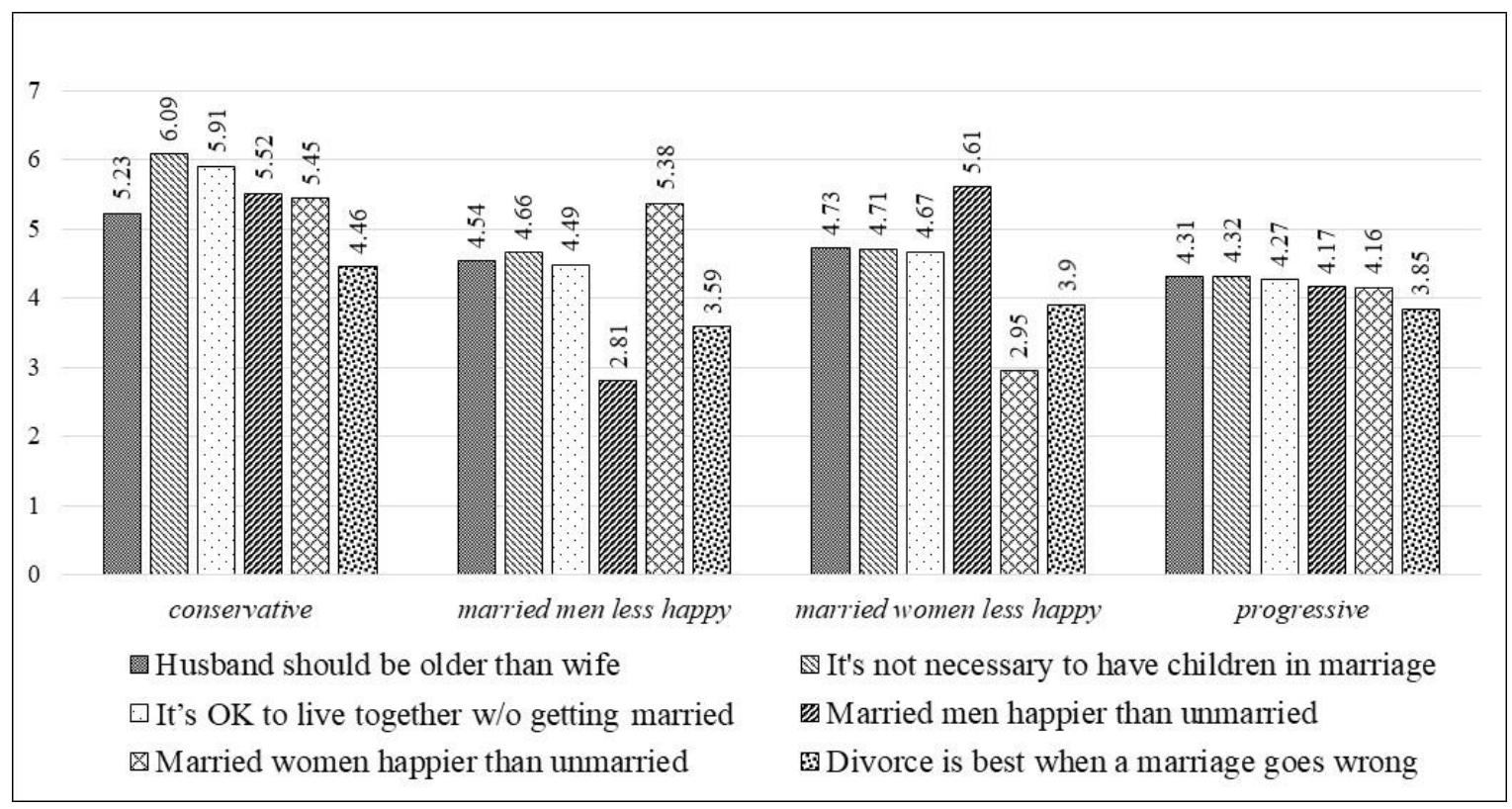




\section{Vita}

Kwangman Ko was born and grew up in Asan-si, Chungcheongnam-do, South Korea on January 22, 1973. He attended Hanyang University at Seoul and received B.S. and M.S. in Urban Planning in 1998 and 2000, respectively. After that, he had worked at a Real Estate Company and a construction company for five years. While changing his career to the field of Psychology and Education, Kwangman received B.A. in Counseling Psychology in 2007 from Seoul Digital University at Seoul and B.A. in e-Lifelong Education in 2010 from Gukje Cyber University at Kyunggi-do. He also attended Yonsei University at Seoul and received his M.A. in Child and Family Studies in 2012. Then he came to the United States and joined the doctoral program in the Department of Human Development and Family Science at the University of Missouri in 2013. Kwangman completed his doctoral work in Human Development and Family Science and pursued his Ph.D. in Human Environmental Science at the University of Missouri in 2018. He also completed the Graduate Minor in Psychological Statistics and Methods at the University of Missouri in 2018. 